\title{
Electrochemical Determination of Cibacron Red FN-R at Glassy Carbon Electrode
}

\author{
A.-E. Radi, ${ }^{1, *}$ M. Mostafa, ${ }^{1}$ T. Hegazy, ${ }^{2}$ R. Elshafey ${ }^{1}$ \\ ${ }^{1}$ Department of Chemistry, Faculty of Science (Dumyat), Mansoura University, \\ 34517 Dumyat, Egypt \\ ${ }^{2}$ Department of Environment Sciences, Faculty of Science (Dumyat), Mansoura University, \\ 34517 Dumyat, Egypt
}

Received 28 August 2010; accepted 26 November 2010

\begin{abstract}
The electrochemical oxidation of cibacron red FN-R (CB) has been studied by cyclic voltammetry (CV) and differential pulse voltammetry (DPV) at a glassy carbon electrode (GCE) in phosphate buffer solutions of $\mathrm{pH}(2.54-11.79)$ used as supporting electrolytes. The voltammetric behaviour showed that the electro-oxidation process gave rise to a single peak at $0.692 \mathrm{~V}$ vs. $\mathrm{Ag}-\mathrm{AgCl}$ using $\mathrm{DPV}$ in phosphate buffer solution at $(\mathrm{pH} 3.34)$. The oxidation process was shown to be irreversible and adsorption-controlled. An analytical method was developed for the determination of cibacron red FN-R in phosphate buffer solution at ( $\mathrm{pH}$ 3.34) as supporting electrolyte. The anodic peak current varied linearly with cibacron red FN-R concentration in the range $2.0 \times 10^{-6} \mathrm{~mol} \mathrm{~L}^{-1}$ to $1.0 \times 10^{-5} \mathrm{~mol} \mathrm{~L}^{-1}$ of cibacron red FN-R with a limit of detection (LOD) of $4.49 \times 10^{-7} \mathrm{~mol} \mathrm{~L}^{-1}$ and limit of quantification (LOQ) of $1.49 \times 10^{-6}$ mol $\mathrm{L}^{-1}$. Validation parameters, such as accuracy, precision and recovery were evaluated. The proposed method was successfully applied to the determination of cibacron red FN-R in synthetic industrial effluents and the analytical results compared well with those obtained by the spectrophotometric method.
\end{abstract}

Keywords: differential pulse voltammetry, glassy carbon electrode, electrochemical oxidation, cibacron red FN-R, reactive red 238.

\section{Introduction}

Natural pigments and synthetic dyes are extensively used in various fields of everyday life, including food production, textile industry, paper production,

\footnotetext{
*Corresponding author. E-mail address: abdradi@yahoo.com
} 
agricultural practice research and water science and technology. A number of synthetic dyes and pigments, which are becoming extensively scattered throughout the environment, has a significant impact on the environment and can cause adverse toxicological side effects; therefore, the need for development of effective, rapid and reliable analytical methods with sufficient detectability to quantify them in different samples should deserve particular attention. Among the several analytical methods, UV-vis spectrophotometry [1], immunoassays [2], and chromatography [3, 4], capillary electrophoresis [5-7], and Raman spectroscopy [8] have been reported. Recently, voltammetric methods in the analysis of reactive dyes have been investigated [9-15], based on electrochemical reduction of azo dyes groups.

To the best of our knowledge, no methods have appeared in the literature based on the electrochemical redox properties of cibacron red FN-R. Thus, the aim of the present work is the investigation of the electrochemical oxidation behavior of the cibacron red FN-R on glassy carbon electrode using cyclic and differential pulse voltammetry, and then developing a voltammetric method for cibacron red FN-R dye determination. The electroanalytical technique provides the advantage of simplicity, low cost, relatively short analysis time and direct analysis, without any extraction, clean-up, or pre-concentration steps.

\section{Experimental \\ Apparatus}

The voltammetry experiments were performed using CHI610C Electrochemical Analyzer controlled by CHI Version 9.09 software (CH Instruments, USA). A three-electrode system was composed of a glassy carbon (BAS model MF-2012, $\Phi=3 \mathrm{~mm}$ ) working electrode, an $\mathrm{Ag} / \mathrm{AgCl} / 3 \mathrm{M} \mathrm{KCl}$ (BAS model MF-2063) reference electrode and a platinum wire (BAS model MW-1032) counter electrode. The working electrode surface was polished with 0.3 and $0.05 \mu \mathrm{m}$ alumina slurries before each measurement. The UV/vis-absorption spectra were recorded on a double beam Perkin Elmer UV-Visible spectrophotometer equipped with a PC for data processing UV Winlab-Ver 2.80.03 (Perkin Elmer USA) using a $1.0 \mathrm{~cm}$ cell at $0.2 \mathrm{~nm}$ intervals, in the range of $200-700 \mathrm{~nm}$. A CG 808 (Schott Gerate, Germany) digital $\mathrm{pH}$-meter with glass combination electrode served to carry out the $\mathrm{pH}$ measurements.

\section{Reagents}

A commercial reactive azo dye, cibacron Red FN-R hetero-bireactive vinylsulphone fluorotriazine dye (CI Reactive Red 238, empirical formula $\mathrm{C}_{29} \mathrm{H}_{15} \mathrm{O}_{13} \mathrm{~S}_{4} \mathrm{ClFN}_{7} \mathrm{Na}_{4}, 944.2 \mathrm{~g} \mathrm{~mol}^{-1}$ ), kindly provided by (Dakahlia Spinning and Weaving (DETEX) Company, Egypt) was used without further purification (80\% purity approx.). Its chemical structure was not disclosed by the manufacturer. Stock solution $\left(1.0 \times 10^{-3} \mathrm{~mol} \mathrm{~L}^{-1}\right)$ was prepared in double distilled water, and stored in a dark bottle. Phosphate buffer solutions were prepared by adding appropriate amounts of o-phosphoric acid; potassium dihydrogen phosphate and disodium hydrogen phosphate in double distilled water [16], were 
used as supporting electrolytes. High-purity reagents were employed in all experiments. All solutions were papered using doubly distilled water.

\section{Procedure}

For voltammetric measurement, $5 \mathrm{~mL}$ of the electrolyte solution were transferred into the voltammetric cell. After measurement of the blank solution in the anodic direction from 0.3 to $1.0 \mathrm{~V}$, the appropriate amount of cibacron Red FN-R solution was added and the anodic potential sweep was carried under different operational parameters. Before each measurement, the glassy carbon electrode was polished manually with $0.5 \mathrm{~mm}$ alumina dispersed in bi-distilled water on a smooth polishing cloth and gently dried with a tissue paper. All measurements were carried out at room temperature. The peak heights were evaluated as the differences between each voltammogram and the background electrolyte voltammogram.

\section{Preparation and analysis of synthetic industrial effluent samples}

The stock solution of cibacron red FN-R $\left(1.0 \times 10^{-4} \mathrm{~mol} \mathrm{~L}^{-1}\right)$ was hydrolysed to convert it to the form in which it is normally found in industrial effluents. The hydrolysis was done by adjusting the $\mathrm{pH}$ to 10.6 , followed by heating to $60{ }^{\circ} \mathrm{C}$ for $1 \mathrm{~h}$, then aliquot solution was transferred to a voltammetric cell containing phosphate buffer ( $\mathrm{pH} 3.34$ ) $0.2 \mathrm{M}$. The differential-pulse voltammogram was subsequently recorded by employing amplitude $50 \mathrm{mV}$, pulse width $50 \mathrm{~ms}$, and sample width, $0.02 \mathrm{~S}$. The content of the dye in synthetic industrial effluents was determined referring to the regression equation.

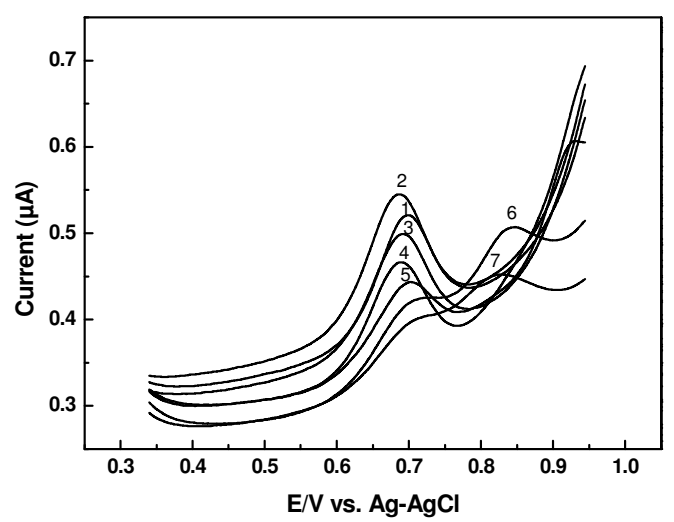

Figure 1. Differential pulse voltammograms for $2.0 \times 10^{-5} \mathrm{~mol} \mathrm{~L}^{-1}$ cibacron red FN-R solution in phosphate buffer of different $\mathrm{pH}$ values (1) $\mathrm{pH} 2.54$, (2) $\mathrm{pH} 3.34$, (3) $\mathrm{pH}$ 4.20, (4) $\mathrm{pH} 5.75$ (5) $\mathrm{pH} 6.70$, (6) $\mathrm{pH} 8.38$ (7) $\mathrm{pH} 8.70$, at glassy carbon electrode. Pulse amplitude, $50 \mathrm{mV}$; pulse width, $30 \mathrm{~s}$; sample width, $0.02 \mathrm{~s}$.

\section{Results and discussion}

Firstly, differential pulse voltammetry was used to characterize the electrochemical behavior of the cibacron at GCE electrode.The electrochemical oxidation of cibacron was studied over a wide $\mathrm{pH}$ range between 2.54 and 8.70. 
The DP voltammograms in Fig. 1 were all recorded in solutions of $2.0 \times 10^{-5} \mathrm{~mol}$ $\mathrm{L}^{-1}$ cibacron in different electrolytes of $0.2 \mathrm{M}$ ionic strength. The compound gave a well-defined single signal up to $(\mathrm{pH} 2.54)$. As the $\mathrm{pH}$ increased, another peak also appeared within $\mathrm{pH}$ range (2.54 to 8.70$)$. No electroactivity was found for ( $\mathrm{pH}>8.70$ ) even for higher concentration, showing that cibacron is not oxidizable in these conditions. Fig. 2 (A and B) also shows the influence of the $\mathrm{pH}$ on the peak potential and peak current of the oxidation steps. The graph of peak (1) shows an independent relationship between $\mathrm{pH}$ and potential, which can be attributed to a fast chemical protonation/deprotonation process. The peak current reached the highest values at $(\mathrm{pH} 3.34)$, and this was selected as the optimum value for quantitative analysis.

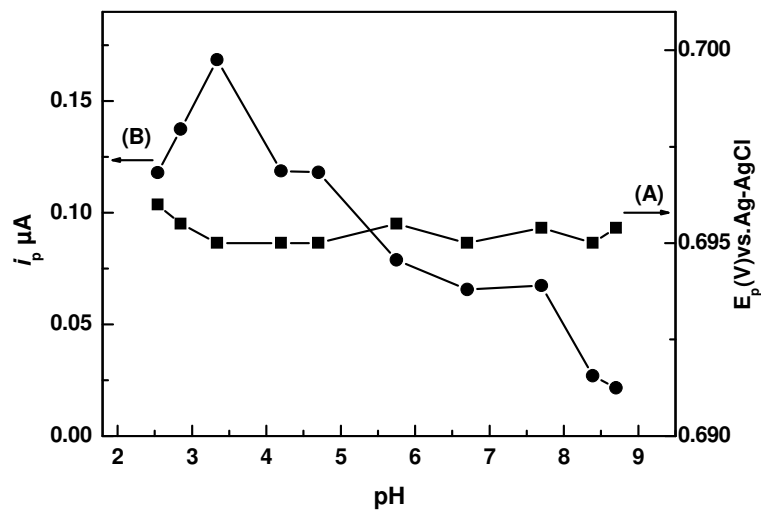

Figure 2. Effect of $\mathrm{pH}$ on (A) peak potential, and (B) peak current in phosphate buffer using differential pulse voltammetry at glassy carbon electrode for $2.0 \times 10^{-5} \mathrm{~mol} \mathrm{~L}^{-1}$ cibacron red FN-R; pulse amplitude, 50mV; pulse width, $30 \mathrm{~s}$; sample width, $0.02 \mathrm{~s}$.

Cyclic voltammetry (CV) is commonly used to determine the reversibility of electrode process. Cyclic voltammograms of the investigated dye at the GCE recorded in the phosphate buffer of various $\mathrm{pH}$ values at various scan rates exhibited the same behavior obtained by DPV. Typical cyclic voltammogram obtained for the oxidation of $5.0 \times 10^{-5} \mathrm{~mol} \mathrm{~L}^{-1} \mathrm{CB}$ in phosphate buffer, $(\mathrm{pH} 3.34)$ on glassy carbon electrode is shown in Fig. 3A. The curve obtained for oxidation of $\mathrm{CB}$ dye presents one anodic peak at $0.798 \mathrm{~V}$. The fact that no peak was observed in the reverse scan suggests that the oxidation process is an irreversible one. The influence of the scan rate $(v)$ ranging $5-60 \mathrm{mVs}^{-1}$ on the peak current was evaluated at $\mathrm{pH}$ 3.34. The plot of $\log i_{\mathrm{p}}$ versus $\log v$ gave a straight line of slope of 0.86 , according to the equation: $\log i_{\mathrm{p}}=\mathrm{A}+\mathrm{B} \log v$, where $\mathrm{A}$ is the intercept and $\mathrm{B}$ is the slope. This indicates that cibacron oxidation at the electrode surface is an adsorption-controlled process [17].

Cibacron red FN-R, showed a positive shift in the peak potential, a further indication of the irreversibility of dye electrochemical oxidation process. Cyclic voltammograms of $\mathrm{CB}$ dye at $(\mathrm{pH} 8.39)$ exhibited two peaks on the forward scan Fig. 3B. No anodic peak appeared on reversing the direction of the voltage sweep just after the initial reduction peak, suggesting the irreversible nature of the electrode reaction under these conditions. 

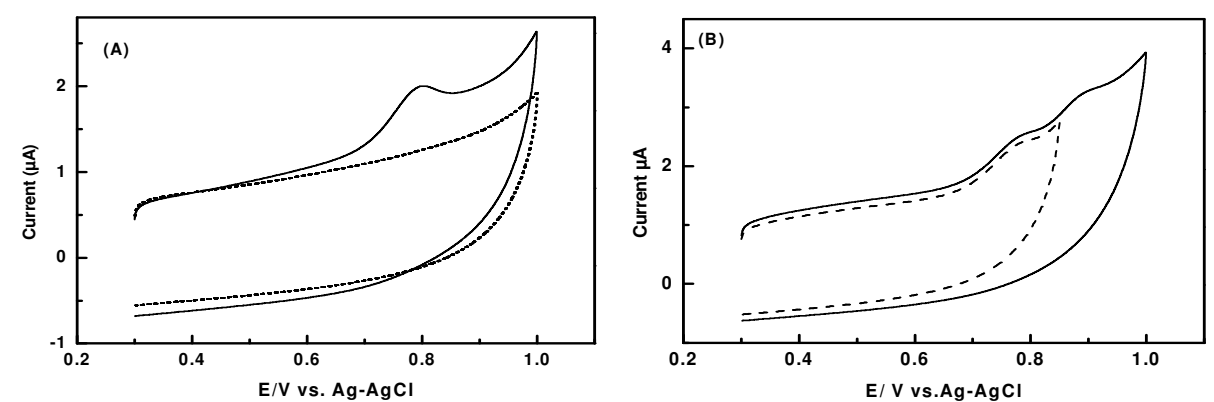

Figure 3. Cyclic voltammograms of $5.0 \times 10^{-5} \mathrm{~mol} \mathrm{~L}^{-1}$ cibacron red FN-R solution on glassy carbon electrode in phosphate buffer (A) at $\mathrm{pH} 3.34$ and (B) at $\mathrm{pH} 8.38(0.2 \mathrm{M})$, scan rate, $50 \mathrm{mVs}^{-1}$; dotted line (......) represents the blank in phosphate buffer; broken line: sweep reversed after first anodic peak.

Based on the voltammetric behavior of cibacron red FN-R, a quantitative method was developed. Differential pulse voltammetry has been used to gather calibration curve data for cibacron red FN-R; as the DPV has well-established advantages, including good discrimination against background current, and low detection and determination limits [18]. Best results were obtained at pulse amplitude $50 \mathrm{mV}$, pulse width $50 \mathrm{~ms}$, and sample width, $0.02 \mathrm{~S}$. A set of DP voltammograms in phosphate buffer $(0.2 \mathrm{M}, \mathrm{pH} 3.34)$, illustrating the variation of peak (1) height with dye concentrations is shown in Fig. 4. A linear range was observed for concentrations between $2.0 \times 10^{-6}$ and $1.0 \times 10^{-5} \mathrm{~mol} \mathrm{~L}^{-1}$. The variation of peak current $\left(i_{\mathrm{pa}}\right)$ with dye concentration is represented by the linear regression equation $i_{\mathrm{pa}}(\mu \mathrm{A})=0.0177+0.0120 \mathrm{C}\left(\mu \mathrm{mol} \mathrm{L}{ }^{-1}\right), \mathrm{R}=0.9988(\mathrm{n}=8)$, where $\mathrm{R}$ is the correlation coefficient and $\mathrm{n}$ is the number of points. Statistical evaluation of the data [19], was performed through determination of the standard deviation of the residuals $\left(\mathrm{S}_{\mathrm{y} / \mathrm{x}}=0.0018\right)$, standard deviation of the intercept $\left(\mathrm{S}_{\mathrm{a}}=\right.$ $0.0015)$, and standard deviation of the slope $\left(S_{b}=2.324 \times 10^{-4}\right)$. The small figures obtained refer to the high precision of the method. The limit of detection (LOD) and the limit of quantitation (LOQ) of cibacron red FN-R were calculated as $4.49 \times 10^{-7} \mathrm{~mol} \mathrm{~L}^{-1}$ and $1.49 \times 10^{-6} \mathrm{~mol} \mathrm{~L}^{-1}$ respectively, by using the equation $\mathrm{LOD}=3 \mathrm{~S}_{\mathrm{y} / \mathrm{x}} / \mathrm{b}$ and $\mathrm{LOQ}=10 \mathrm{~S}_{\mathrm{y} / \mathrm{x}} / b$, the ratio of the standard deviation of $y$ residuals $\left(S_{y x}\right)$ and the slope of the regression line $(b)$.

In order to determine the accuracy and precision of the method, solutions containing three different concentrations at low, medium and high concentrations of linear range (i.e. $3.85,6.54$ and $8.26 \times 10^{-6} \mathrm{~mol} \mathrm{~L}^{-1}$ ) of cibacron red FN-R were prepared and analysed in quintuplicate. The analytical results obtained from this investigation are summarized in (Table 1). The relative standard deviation (RSD $\%)$, recovery and Bias values can be considered satisfactory at levels of concentrations examined. Relative standard deviation usually does not exceed $2.85 \%$ for concentration range $3.85-8.26 \times 10^{-6} \mathrm{~mol} \mathrm{~L}^{-1}$. 


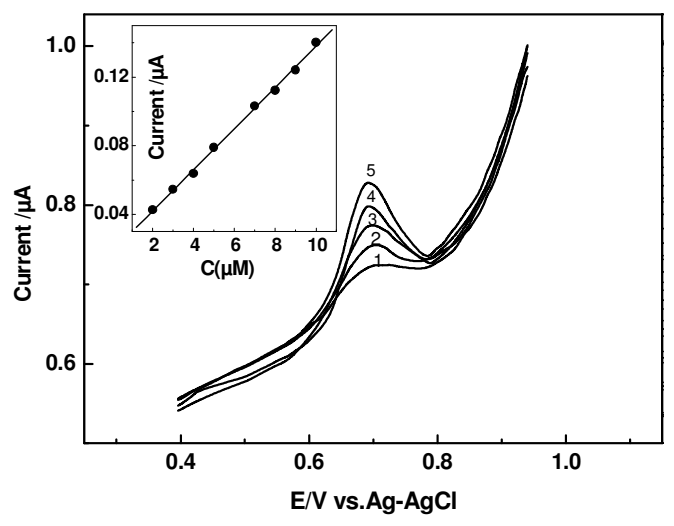

Figure 4. Differential pulse voltammograms (DPVs) for increasing concentration of cibacron red FN-R in phosphate buffer $\mathrm{pH}=3.34(0.2 \mathrm{M})$ : (1) $2.0 \times 10^{-6}$, (2) $3.0 \times 10^{-6}$, (3) $7.0 \times 10^{-6}$, (4) $9.0 \times 10^{-6}$ and (5) $1.0 \times \times 10^{-5} \mathrm{~mol} \mathrm{~L}^{-1}$. Pulse amplitude, $50 \mathrm{mV}$; pulse width, $30 \mathrm{~s}$; sample width, $0.02 \mathrm{~s}$. Inset is the calibration plot.

Spectrophotometric measurements of cibacron Red FN-R in $5.0 \times 10^{-7}$ to $1.0 \times 10^{-5}$ mol $\mathrm{L}^{-1}$ in the range 200-700 $\mathrm{nm}$ showed three maxima absorbance: 287.42 , 329.73 and $545.61 \mathrm{~nm}$ (Fig. 5). The higher absorbance was obtained at 545.61 $\mathrm{nm}$. The visible band at $545.61 \mathrm{~nm}$ is attributed to the azo bonds and responsible for the red colour of the solution [20].

Table 1. Accuracy and precision data for cibacron red FN-R obtained by differentialpulse voltammetric (DPV) method.

\begin{tabular}{|c|c|c|c|c|c|}
\hline $\begin{array}{c}\text { Added } \\
\left(\mathrm{mol} \mathrm{L}^{-1}\right)\end{array}$ & $\begin{array}{c}\text { Found } \\
\left(\mathrm{mol} \mathrm{L}^{-1}\right) \overline{\mathrm{x}}^{a}\end{array}$ & $\begin{array}{c}\text { Standard deviation, } \\
\text { S.D. }\end{array}$ & $\begin{array}{l}\text { Relative standard } \\
\text { deviation, RSD } \%^{b}\end{array}$ & $\begin{array}{l}\text { Accuracy } \\
\text { bias } \%^{c}\end{array}$ & $\begin{array}{c}\text { Recovery } \\
\%\end{array}$ \\
\hline $3.85 \times 10^{-6}$ & $3.86 \times 10^{-6}$ & 0.11 & 2.85 & -0.26 & 100.25 \\
\hline $6.54 \times 10^{-6}$ & $6.52 \times 10^{-6}$ & 0.08 & 1.22 & 0.31 & 99.69 \\
\hline $8.26 \times 10^{-6}$ & $8.21 \times 10^{-6}$ & 0.17 & 2.07 & 0.61 & 99.39 \\
\hline
\end{tabular}

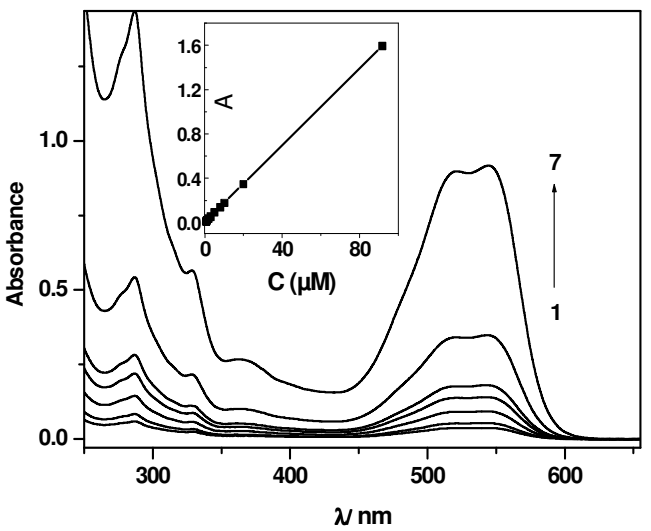

Figure 5. UV-Vis spectra of cibacron red FN-R at different concentrations from $5.0 \times 10^{-7}$ to $1.0 \times 10^{-5} \mathrm{~mol} \mathrm{~L}^{-1}$ in phosphate buffer $\mathrm{pH}=8.39(0.1 \mathrm{M})$. Inset: calibration plot of cibacron red FN-R at $\lambda \max =545.61 \mathrm{~nm}$. 
A UV-Vis spectrophotometric method was developed for the determination of cibacron red FN-R and the results were compared. Fig. 5 shows the UV-Vis spectrum of cibacron red FN-R and the calibration plot obtained between the concentration and the absorbance values. The determination limits were $4.54 \times 10^{-7} \mathrm{~mol} \mathrm{~L}^{-1}$ and $1.52 \times 10^{-6} \mathrm{~mol} \mathrm{~L}^{-1}$ and the RSD value at $3.0 \times 10^{-6} \mathrm{~mol} \mathrm{~L}^{-1}$ CB dye was $0.612 \%$.

The differential-pulse voltammetric technique (DPV) has been applied to determine cibacron red FNR dye sample containing $50 \mathrm{mg}$ dye per $50 \mathrm{~mL}$. The results of the proposed technique have been evaluated statistically as compared with results of UV-spectrophotometeric method (Table 2). There was no significant difference between the mean values and precision of the two methods at $95 \%$ confidence level.

The proposed voltammetric method was successfully applied for the assay of cibacron red FN-R in spiked synthetic industrial effluents. Five determinations of this dye concentration gave an average cibacron red FN-R concentration (6.48 $\times 10^{-6}$ mol L ${ }^{-1}$ ) corresponding to a mean recovery of $99.04 \%$. The relative standard deviation was $2.06 \%$ indicating adequate precision and accuracy of the proposed method.

Table 2. Data of DPV and UV-spectrophotometric methods for determination of cibacron red FNR dye.

\begin{tabular}{ccc}
\hline Item & DPV & Spectrophotometric method \\
\hline Mean $(\%)$ & 100.296 & 99.576 \\
S.D. & $9.17 \times 10^{-4}$ & $3.83 \times 10^{-4}$ \\
$\mathrm{~N}$ & 7 & 7 \\
$t$-test of significance & $1.08\left(2.18^{\mathrm{a}}\right)$ & \\
$F$-test of significance & $5.72\left(4.284^{\mathrm{a}}\right)$ & \\
\hline \multicolumn{2}{c}{${ }^{\mathrm{a}}$ The tabulated $t$ - and $F$-values, respectively, at $\mathrm{P}=0.05$}
\end{tabular}

\section{Conclusion}

The electrochemical behaviour of Cibacron red FN-R was studied at glassy carbon electrode by cyclic and differential pulse voltammetry. The cibacron red FN-R showed an irreversible oxidation peak/peaks. The electrochemical process is adsorption controlled. Our findings indicate that the developed differential pulse voltammetric method provides the advantage of simplicity, precision and reliability, and shows to be capable of determining cibacron red FN-R at very low levels. This method was proposed for the determination of the dye in spiked synthetic industrial effluent samples and the results are satisfactory. 


\section{References}

1. H. Zollinger, Color in chemistry, 2nd ed., C.C.H Publisher, New York, 1991.

2. M. Joelsson, G. Johansson, Enzyme Microb.Tech. 9 (1987) 233-237. 10.1016/0141-0229(87)90022-6

3. P. Santambien, S. Sdiqui, E. Hubert, P. Girot, A.C. Roche, M. Monsigny, E. Boschetti, J. Chromatogr-Biomed. Appli. 664 (1995) 241-246. 10.1016/03784347(94)00419-6

4. P. Santambien, P. Girot, I. Hulak, E. Boschetti. J. Biochem. Biophys. Methods 24 (1994) 285-295. 10.1016/0165-022X(94)90080-9

5. A.L. Revilla, H. Chroma-Keull, J. Havel, J. Capill. Electrophor. Microchip Technol. 7 (2002) 67-72.

6. T. Poiger, S.D. Richardson, G.L. Baughman, J. Chromatogr. A 886 (2000) 271-282. 10.1016/S0021-9673(00)00482-9

7. K.N. Tapley, J. Chromatogr. A 706 (1995) 555-562. 10.1016/00219673(94)01206-T

8. $\quad$ S. Kokot, N. Anh, T.L. Rintoul, Appl. Spectrosc. 51 (1997) 387-395.

9. C.C.I. Guaratini, A.G. Fogg, M.V.B. Zanoni, Electroanal. 13 (2001) 15351543. 10.1002/1521-4109(200112)13:18<1535::AID-ELAN1535>3.0.CO;2-H

10. P.J. Almeida, J.A. Rodrigues, A.A. Barros, A.G. Fogg, Anal. Chim. Acta 385 (1999) 287-293. 10.1016/S0003-2670(98)00586-8

11. A.R.H.M. Yusoff, A.G. Fogg, R. Ahmad, Talanta 47 (1998) 797-801. 10.1016/S0039-9140(98)00089-7

12. M.V.B. Zanoni, A.G. Fogg, J. Barek, J. Zima, Anal. Chim. Acta 349 (1997) 101-109. 10.1016/S0003-2670(97)00268-7

13. A.G. Fogg, A. Rahim, H.M. Yusoff, R. Ahmad, Talanta 44 (1997) 125129. 10.1016/S0039-9140(96)02014-0

14. M.V.B. Zanoni, A.G. Fogg, J. Barek, J. Zima, Anal. Chim. Acta 315 (1995) 41-54. 10.1016/0003-2670(95)00285-8

15. U. Sahm, D. Knittel, E. Schollmeyer, Fresenius' J. Anal. Chem. 338 (1990) 824-830. 10.1007/BF00323196

16. G.D. Christian, W.C. Purdy, J. Electroanal. Chem. 3 (1962) 363-367.

17. D.K. Gosser, Cyclic voltammetry, VCH, New York, 1994.

18. A.J. Bard, L.R. Faulkner, Electrochemical methods:fundamentals and applications, Wiley, New York, 2001.

19. J.C. Miller, J.N. Miller, Statistics for Analytical Chemistry, Ellis Horwood Series, PTR Prentice Hall, New York, London, 1993, p.119.

20. R.M.C. Silverstein, G.C. Bassler, T.C. Morril, Spectrophotometric Identification of Organic Compounds, Wiley, New York, USA, 1991. 